\title{
Hypertension Therapeutics Update: A Brief Clinical Summary on Azilsartan, Cilnidipine and Nebivolol
}

\author{
Sanjeev Sharma
}

\begin{abstract}
Uncontrolled hypertension is the major risk factor for cardiovascular disease. The economic burden of disease is enormous in developed as well as in developing countries. The epidemiological studies have explained many etiological factors associated with chronic untreated hypertension, which varies according to geography and ethnicity.

In last five decades, many classes and types of antihypertensive drugs have been developed. This pharmacological review provides an update on new molecules belonging to three pharmacological classes of antihypertensives-angiotensin receptor blocker (azilsartan), calcium channel blocker (cilnidipine) and beta blocker (nebivolol) and their clinical implications.
\end{abstract}

Keywords: Azilsartan, Calcium channel L/N-type, Cilnidipine, Hypertension, Nebivolol, Newer drugs for hypertension, Vasodilation with Nebivolol.

How to cite this article: Sharma S. Hypertension Therapeutics Update: A Brief Clinical Summary on Azilsartan, Cilnidipine and Nebivolol. Hypertens J 2015;1(2):111-117.

\section{Source of support: Nil}

Conflict of interest: None

\section{INTRODUCTION}

Chronic untreated hypertension is a major risk factor for excessive mortality and premature morbidity across the world including India. In the last 2 decades, India has witnessed increasing prevalence of cardiovascular disease (CVD), mainly driven by uncontrolled hypertension. The economic and human costs of hypertension and CVD are enormous with a direct adverse impact on public health in India. While there may be many explanations and theories as to the etiological factors contributing to the escalating prevalence of CVD in India, suffice it to acknowledge that altered life-style and high blood pressure are the principal contributors. We have to acknowledge that the endemic of CVD in India will

\section{Clinical Pharmacologist}

Apollo Research and Innovations, Pharmacy, Apollo Indraprastha Hospital, New Delhi, India

Corresponding Author: Sanjeev Sharma, Clinical Pharmacologist, Apollo Research and Innovations, Pharmacy Apollo Indraprastha Hospital, New Delhi, India, e-mail: sanjeevsham@yahoo.co.uk only get worse with time unless we identify and tackle the precipitating risk factors. Among the accepted risk factors for CVD, hypertension is the most prevalent one and which can be diagnosed and treated without much difficulty or expensive evaluation. Thus, at the present time, we have sufficient tools to diagnose and treat hypertension in any clinical setting.

In the management of hypertension, the first step would be to educate the patients and introduce lifestyle changes. However, a majority of patients with hypertension are unable to or unwilling to follow nonpharmacological (hygienic) measures and thus require pharmacological therapy to achieve recommended blood pressure goals. In the last 5 decades, we have seen development and application of various classes and types of antihypertensive drugs. One can surmise that, at the present time, antihypertensive drug therapy has 'matured'. Armed with the knowledge of pharmacological options to treat hypertension, healthcare providers should be able to treat uncomplicated hypertension with considerable ease. This brief pharmacological review will provide an update on some recent acquisitions in antihypertensive drug therapy which widens the scope for effective management of hypertension. The review will selectively cover new molecules belonging to three pharmacological classes-angiotensin receptor blockers (ARBs), calcium channel blockers (CCBs) and betablockers ( $\beta$-blockers) (Table 1).

\section{AZILSARTAN-A NEW GENERATION ARB}

Angiotensin receptor blockers are proven and effective class of drugs beneficial in the treatment of hypertension, CVD, and comorbidities, such as diabetes and chronic kidney disease (CKD) ${ }^{1,2}$ By inhibiting the actions of angiotensin II at the blood vessel and other sites, ARBs reduce the systemic vascular resistance and aldosterone production (Figs 1 and 2). Thus, ARBs reverse one or more mechanisms of hypertension. In general, ARBs have a long track record of safety, efficacy, and target organ protection in hypertension while providing considerable freedom from adverse effects. ${ }^{3}$

Azilsartan is a new ARB indicated for the treatment of hypertension. It has been proposed that azilsartan due to its pharmacological and pharmacodynamic 


\begin{tabular}{l} 
Table 1: Newer drugs for hypertension \\
\hline Azilsartan, new ARB \\
Long acting \\
Tight binding to the receptor \\
Potent \\
Once daily \\
Very effective \\
Cilnidipine, new CCB \\
Dual mechanism of action \\
Potent \\
Once daily \\
As effective as amlodipine for blood pressure control \\
Cardiorenal protective actions \\
Nebivolol, new $\beta$-blocker \\
Vasodilating $\beta$-blocker \\
Dual mechanism of action \\
Once daily \\
Favorable effects on glucose metabolism \\
Well tolerated
\end{tabular}

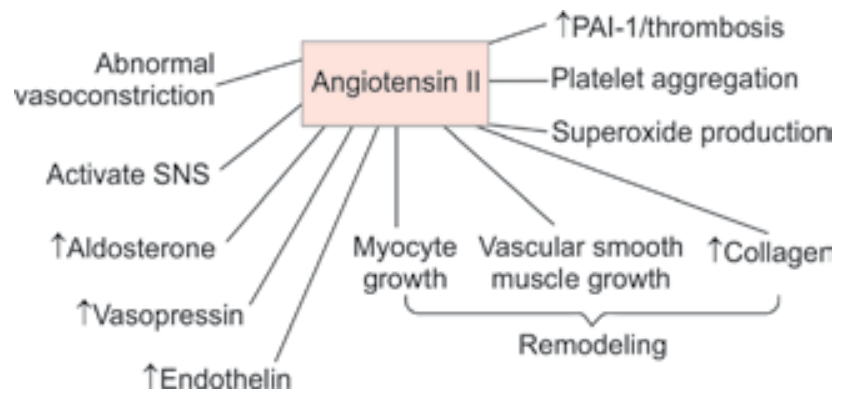

Fig. 1: Pathophysiological effects of angiotensin II

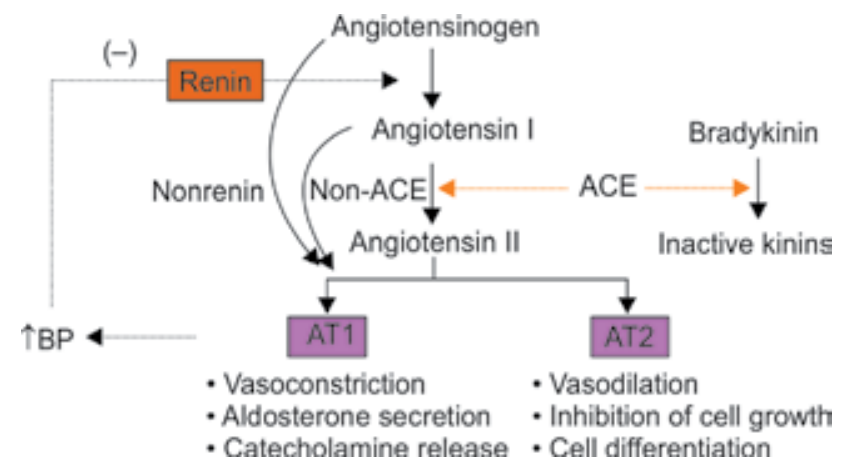

Fig. 2: Renin-angiotensin-aldosterone system

properties is more potent and powerful in comparison to other ARBs given in comparable doses. ${ }^{4,5}$ For example, studies have demonstrated that azilsartan induces greater reductions in blood pressure compared to olmesartan which is considered as the most effective among the ARBs. ${ }^{6,7}$ It appears that azilsartan is more effective than olmesartan and valsartan in the treatment of hypertension. Azilsartan provides 2 to $4 \mathrm{~mm} \mathrm{Hg}$ further reduction in blood pressure compared to other ARBs. The potency of azilsartan (compared to other ARBs) is due to its affinity to bind to the AT1 receptor. The 'tight' binding of azilsartan to AT1 receptor makes it a long

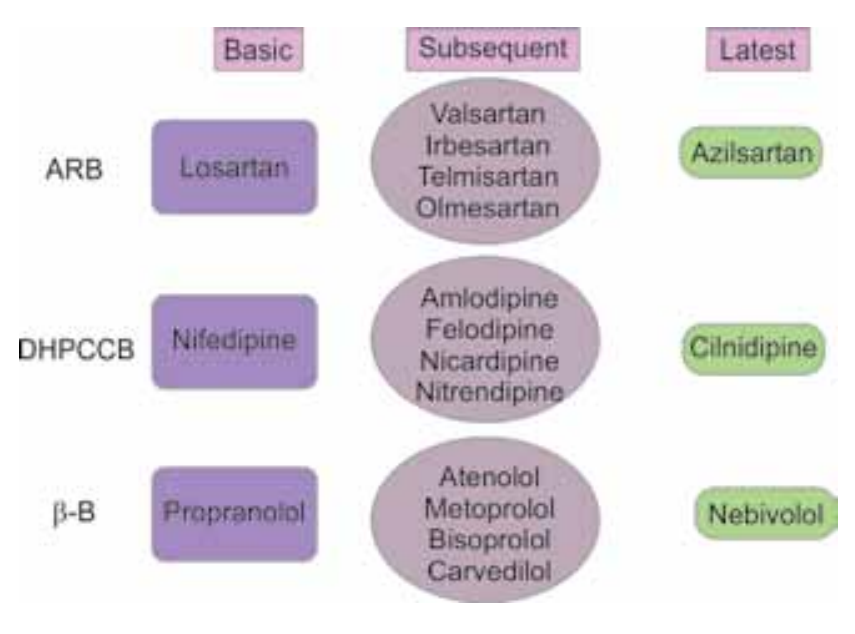

Fig. 3: Newer drugs for hypertension

acting powerful ARB. Azilsartan has $>10,000$ fold affinity for the AT1 receptor than for the AT2 receptor and is more lipophilic with greater bioavailability (Fig. 3).

\section{CLINICAL IMPLICATIONS}

Because of the close relationship between the levels of blood pressure and cardiorenal-neurological risk, aggressive control of hypertension to goal levels is strongly recommended. For a reduction of $5 \mathrm{~mm} \mathrm{Hg}$ in diastolic blood pressure, the risk of stroke is reduced by $34 \%$ and ischemic heart disease by $21 \%$. It is possible to achieve therapeutic targets in clinical practice only with drugs or drug combinations which are potent. Azilsartan in the dose range of 40 to $80 \mathrm{mg} /$ day produces significant reduction in the blood pressure levels and thus may reduce the chronic disease burden. ${ }^{8,9}$ The optimal dose of azilsartan is $80 \mathrm{mg} /$ day although a lower dosage $(40 \mathrm{mg}$ ) can be utilized for patients on diuretics and other antihypertensive drugs. Angiotensin receptor blockers have a useful role in the management of hypertension and its complications. ${ }^{10}$

\section{CILNIDIPINE-A NEW GENERATION CALCIUM CHANNEL BLOCKER}

It is an established fact that dihydropyridine (DHP) CCBs are considered as a predictably efficacious drugs to treat hypertension. Calcium influx into the vascular cells provokes vasoconstriction and this phenomenon of calcium influx increases the systemic vascular resistance (SVR) thereby elevating the blood pressure level. So, inappropriate and abnormal calcium influx into the blood vessel has been suggested as one of the major mechanisms in hypertension. The pharmacological probing of this mechanism led to the discovery and development of CCBs for the treatment of hypertension. ${ }^{11}$ Clinical experience and studies have confirmed CCBs 
as one of the most effective classes of antihypertensive drugs. Dihydropyridine CCBs are extremely effective in the treatment of hypertension.

The earlier generations of DHP CCBs include drugs, such as nifedipine, felodipine, nicardipine, nitrendipine, and amlodipine. These illustrative CCBs have served well over the years for the treatment of hypertension and CVD. Outcome studies with CCBs in hypertension have been consistently favorable. The early generations of CCBs, such as amlodipine typically block the L-type calcium channels at the blood vessel site and cause vasodilation. Thus, the single mechanism of action of traditional CCBs is mediated by the blockade of vascular L-type calcium channels.

While the traditional CCBs, such as nifedipine and amlodipine, continue to have a respectable place in antihypertensive drug therapy, their long-term utility may be curtailed by certain adverse effects-ankle edema, activation of the sympathetic nervous system (SNS) and occasional tachycardia. Persistence of these side effects may contribute to patient complaints and nonadherence to therapy. Adherence to indicated therapy is one of the crucial objectives in the management of hypertension and CVD.

\section{CILNIDIPINE-A NEW CCB}

Cilnidipine is a relatively new DHP CCB indicated for the treatment of hypertension. It is characterized as a 'novel' calcium antagonist due to its dual mode of action on the calcium channels (Figs 4 and 5). Cilnidipine blocks both the L-type and N-type calcium channels. The blockade of L-type calcium channel is similar to other DHPs; however, it also blocks the N-type channel at the sympathetic nerve ending. ${ }^{12-14}$ Simultaneous blockade of the L-type and N-type calcium channels results in significant reduction of the blood pressure without causing reflex tachycardia. The dual mode of action of cilnidipine permits vasorelaxation and 'gentle' sympathetic blockade. The later consequence causes a modest reduction in the heart rate and nonepinephrine levels. One can surmise then that cilnidipine is a 'two-inone' molecule-calcium channel inhibition plus gentle suppression of SNS.

The novel mechanism of cilnidipine represents a therapeutic advance in the treatment of hypertension on the basis of solid pharmaceutical science. By inhibiting the action of N-type calcium channel, cilnidipine dilates both arterioles and venules-a property responsible for the absence of ankle edema with the drug. Cilnidipine is highly lipophilic and occupies the binding site avidlyleading to a prolonged and desirable antihypertensive effect. The blood pressure control with cilnidipine is maintained for 24-hours or longer.

\section{CLINICAL IMPLICATIONS}

A substantial percentage of patients with hypertension require inclusion of a DHP CCB for optimal blood pressure control. Calcium channel blockers either as monotherapy or as combination therapy have become a highly reliable class of antihypertensive agents. While the

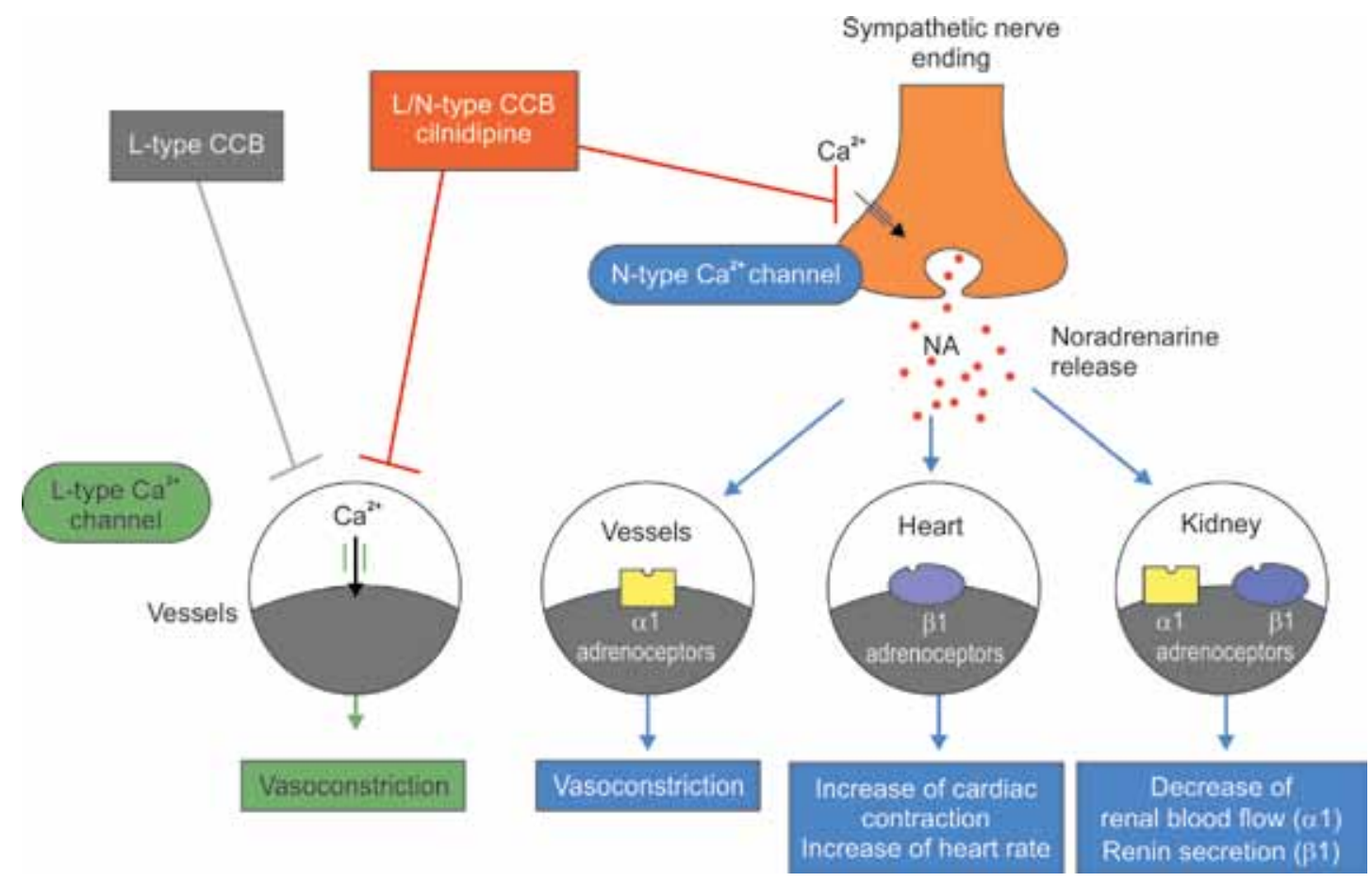

Fig. 4: Mechanism of cilnidipine action 


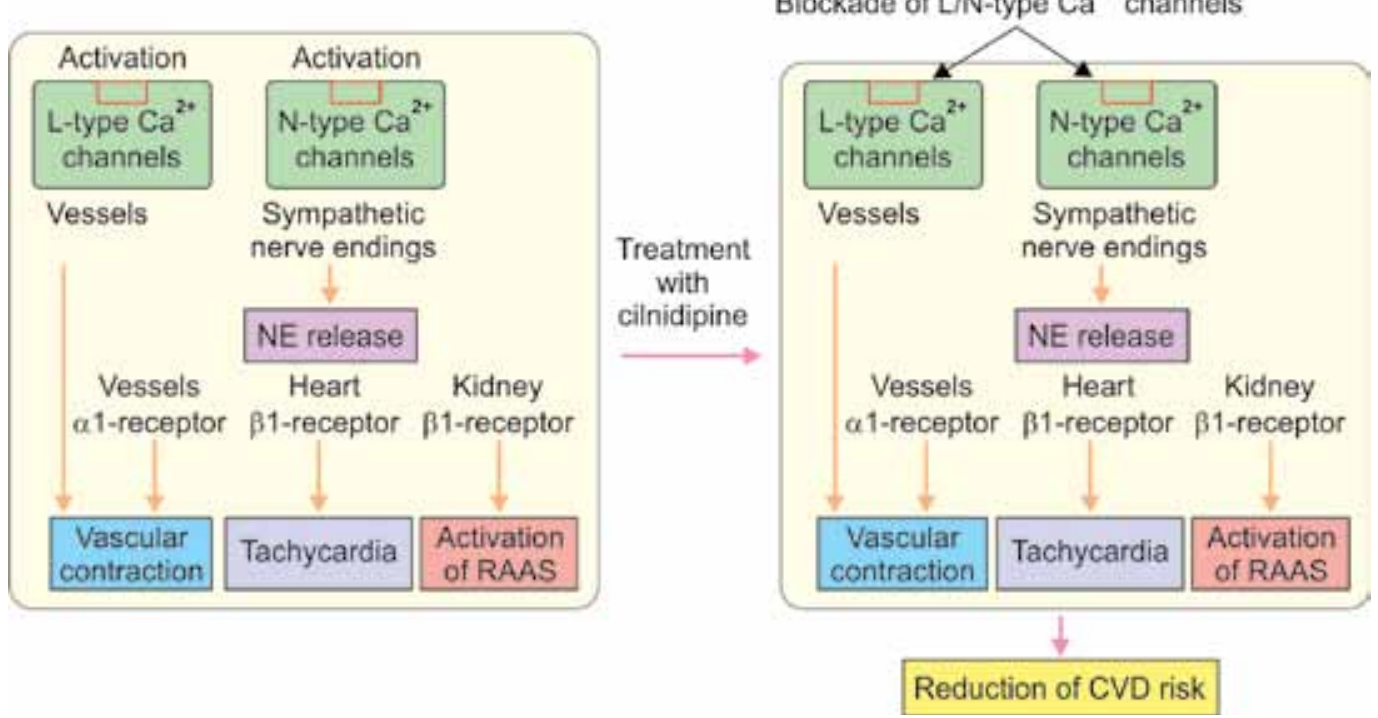

Fig. 5: Calcium channel L/N-type dual action of cilnidipine

efficacy and positive outcomes with traditional CCBs is unquestionable, their side-effect profile and tolerability may impair patients' acceptance and compliance. In this context, the availability of cilnidipine is advantageous as a broad spectrum of antihypertensive drug regimens. Whereas cilnidipine is as efficacious as amlodipine, the former clearly offers some advantages-lack of SNS activation, fewer adverse effects, and less ankle edema. ${ }^{15-17}$ These clinical effects are likely to improve patient compliance and tolerability.

Unlike other DHP CCBs, cilnidipine reduces proteinuria in patients with diabetes or chronic kidney disease (CKD). The antiproteinuria effect of cilnidipine is likely due to its vasodilatory actions on both the preand postglomerular arterioles causing a reduction in the intraglomerular pressure, thereby decreasing the proteinuria. In contrast, traditional DHP CCBs may increase the proteinuria due to selective L-type calcium channel blockade which causes an increase in the intraglomerular pressure (and proteinuria). The dual blockade of L-type and N-type calcium channels in the kidney by cilnidipine explains its possible renoprotective actions. $^{18-21}$

The inhibition of N-type calcium channel by cilnidipine bestows positive cardiovascular results-slight reduction in the heart rate and an improvement in the cardiac function. Thus, the pathophysiological implications of hypertension on the cardiovascular system are offset and reversed by cilnidipine. The contractile and relaxation functions of the heart are preserved and enhanced by cilnidipine. Catecholamine release and platelet activation are inhibited by cilnidipine adding to its beneficial cardiovascular therapeutic profile.
Cilnidipine in the dose range of 5 to $20 \mathrm{mg} /$ day produces a significant fall in blood pressure comparable to that of amlodipine. It can be used either as monotherapy or in combination with diuretics beta-blockers, or ARBs in the treatment of hypertension. ${ }^{22}$ By the virtue of its pharmacological dual mode of action, cilnidipine offers certain advantages over conventional CCBs_-cardiac and renal protection and possible freedom from ankle edema and reflex tachycardia.

\section{NEBIVOLOL-A NEW GENERATION $\beta$-BLOCKER}

Among the cardiovascular drugs, $\beta$-blockers rank as one of the widely used drugs with a vast clinical experience spanning for over 3 decades. In clinical practice, $\beta$-blockers have been the gold standard in the management of patients with hypertension, CVD, congestive heart failure (CHF) and other related comorbidities. In the genesis of hypertension, ischemic heart disease (IHD), and congestive heart failure, sympathetic overactivity has been implicated. Excessive activity of the sympathetic nervous system (SNS) results in vasoconstriction, increased cardiac work and cardiovascular dysfunction. Various markers and signs of SNS overactivity have been demonstrated in patients with hypertension and associated CVD. Therefore, $\beta$-blockers were developed to attenuate the effects of sympathetic overactivity on the cardiovascular system. $\beta$-blockers, however, do not constitute a homogenous group but heterogenous depending on ancillary pharmacological properties, such as $\beta 1$-selectivity, lipid (or water) solubility, membrane stabilizing-activity, intrinsic sympathomimetic activity, and vasodilatory actions (Table 2 and Fig. 6). Hence, 
Table 2: Beta-blockers

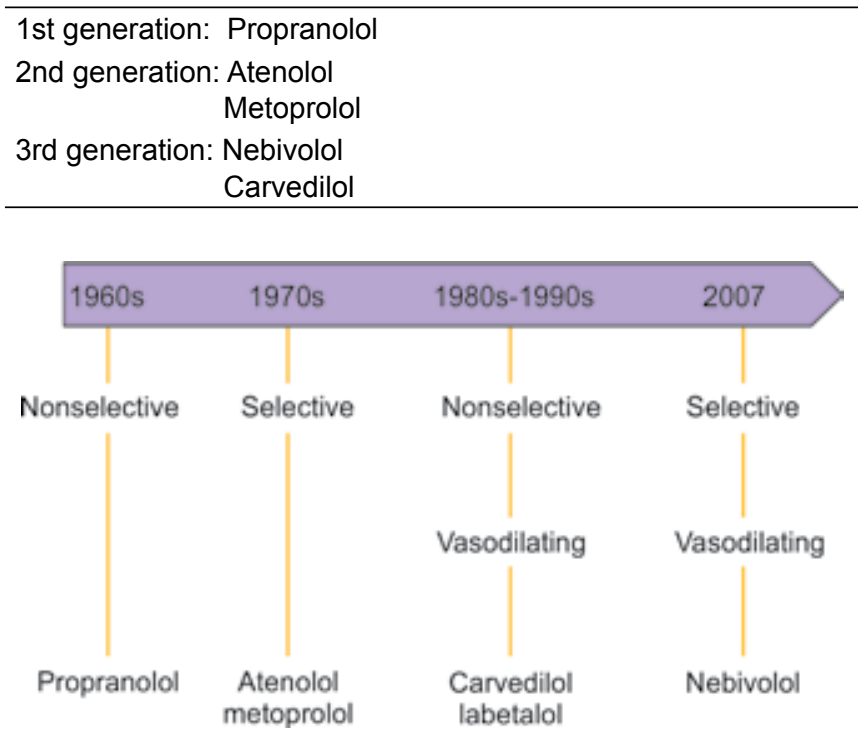

Fig. 6: The evolution of $\beta$-blockers

$\beta$-blockers should not be clubbed together. Each $\beta$-blocker is characterized and individualized on the basis of its inherent pharmacological and pharmacodynamic effects. Propranolol is the very first $\beta$-blocker used in clinical practice. Subsequently, additional $\beta$-blockers became available, such as atenolol, metoprolol, bisoprolol, labetalol, carvedilol, and more recently nebivolol. ${ }^{23-25}$

The primary indication for the use of $\beta$-blockers is and has been hypertension but there are additional indications, such as ischemic heart disease and congestive heart failure. The enthusiasm and popularity of $\beta$-blockers decreased somewhat after the publication of meta-analysis concluding that atenolol-based therapies did not offer cardiovascular protection. Although, atenolol was the main drug implicated in the lack of target organ protection, the entire class of $\beta$-blockers received negative publicity prompting their declining use. The negative perceptions about $\beta$-blockers as a class led various hypertension guidelines to downgrade them as less preferred for the initial treatment of hypertension. Such an unwarranted general categorization of $\beta$-blockers created much controversy and confusion among the clinicians. With the advent of 'vasodilating' new generation drugs, such as nebivolol, there is a revival and renewed utility of $\beta$-blockers in clinical medicine. The old glory of $\beta$-blockers is likely restored by nebivolol due to its unique mechanism(s) of action. ${ }^{26-28}$

\section{NEBIVOLOL-A NEW $\beta$-BLOCKER}

Nebivolol is the latest $\beta$-blocker available for the treatment of hypertension. It is highly cardioselective ( $\beta 1)$ and also promotes the actions of nitric oxide (NO) on the cardiovascular system. Nebivolol is a vasodilating new

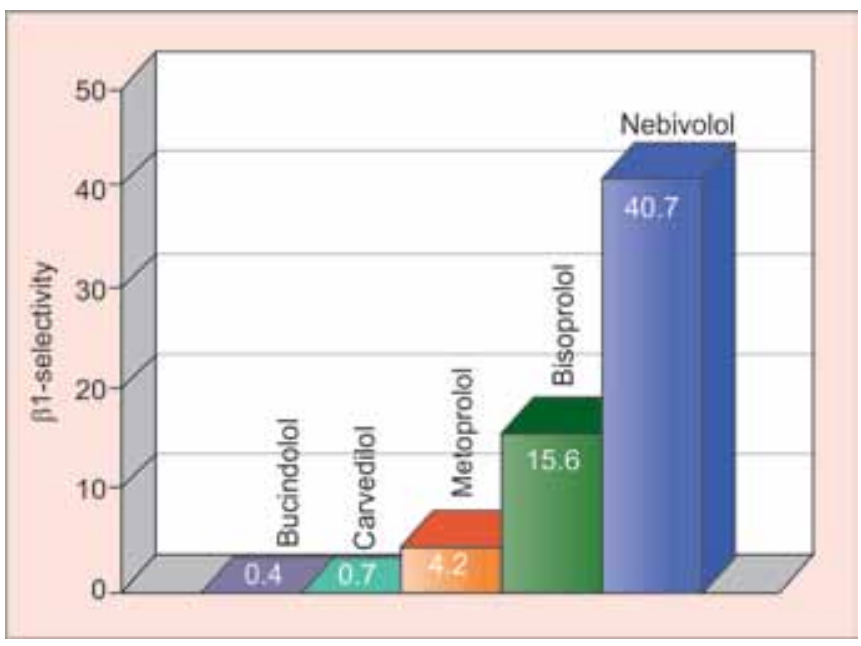

Fig. 7: Cardioselectivity of different $\beta$-blockers

(Source: Brixius K. Br J Pharmacol 2001;193:1330-1338)

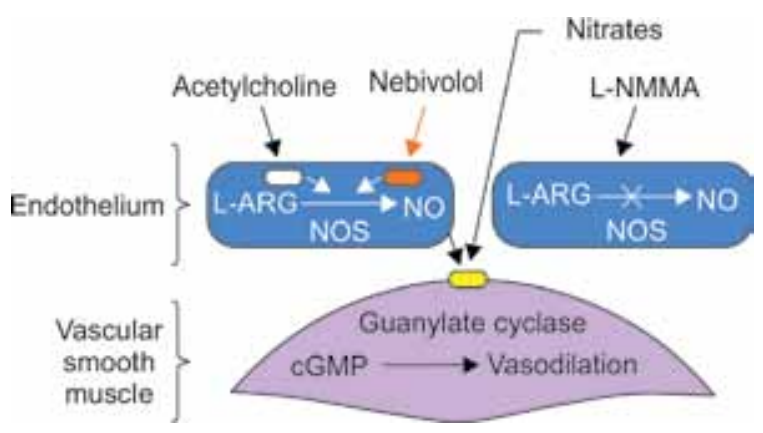

Fig. 8: Endothelial-dependent vasodilation with nebivolol (cGMP: Cyclic guanosine monophosphate; L-ARG: L-Arginine; NOS: Nitric oxide synthase)

generation $\beta$-blocker with a dual mechanism of action- $\beta 1$ blockade plus augmentation of $\mathrm{NO}$ action (Figs 7 and 8). ${ }^{29-31}$ The result is a remarkable fall in blood pressure coupled with positive results on tissue blood flow and metabolic parameters (glucose and lipids). Many side-effects of traditional $\beta$-blockers are caused by their inhibition of $\beta 2$-adrenergic receptors. For example, blockade of $\beta 2$-adrenergic receptors may cause insulin resistance, dyslipidemia and bronchospasm. For this reason, selective $\beta 1$-adrenergic blockade produces fewer side effects (if any) on lipids, glucose, tracheobronchial function and erectile function. ${ }^{32-34}$

Nebivolol has a superior therapeutic profile compared to other $\beta$-blockers due to its dual mechanism of action- $\beta 1$-selectivity and NO mediated vasodilation. Furthermore, nebivolol does not decrease the cardiac output. Preservation of cardiac output in concert with enhancement of endothelial function makes nebivolol a well tolerated drug; physical activity, exercise endurance, and sexual function are not likely to be impaired by nebivolol. It may also be the right $\beta$-blocker for hypertensive patients with concurrent metabolic disorders, such as diabetes and dyslipidemia. Thus, nebivolol is a broad spectrum $\beta$-blocker. It can be used either as monotherapy 
or in combination with other antihypertensive drugs, particularly with diuretics or DHP CCBs. In one outcome trial, patients with CHF benefited when nebivolol was added to the standard treatment. ${ }^{35,36}$

\section{CLINICAL IMPLICATIONS}

The history and utility of $\beta$-blockers experienced ups and downs on the basis of misinformation, some truths, and many half-truths. ${ }^{37,38}$ The popularity of $\beta$-blockers declined after the publication of meta-analyses concluding that $\beta$-blockers (mainly atenolol). The original premise of $\beta$-blockers actions, however, has not been challenged.

With advances in biochemical pharmacology, $\beta$-blockers are reborn with the synthesis and development of nebivolol. ${ }^{39}$ The unique and novel mechanism(s) by which nebivolol works sheds new light on cardiovascular therapeutics. We are now rationally positioned to utilize newer $\beta$-blockers for the benefit of patients with hypertension and CVD. In addition to the cardiovascular advantages, nebivolol also exerts a favorable effect on metabolic parameters, is well tolerated, and free of traditional side-effects of $\beta$-blockers. The net actions of nebivolol preserve the cardiac output while lowering the systemic vascular resistance-the hallmark of hypertension.

In the dose range of 5 to $20 \mathrm{mg} /$ day, nebivolol given once a day exerts a significant antihypertensive effect. It may also improve left ventricular function. Nebivolol also improves endothelial function with obvious implications on microcirculation and tissue blood flow. The reduction of central aortic blood pressure by nebivolol is an important finding with possible implications for cardiovascular outcomes in patients with hypertension. With the new understanding about the pathophysiology of hypertension and the appreciation of pharmacological advances, nebivolol due to its novel mechanism(s) of action is an attractive therapeutic option in the management of hypertension and CVD.

\section{REFERENCES}

1. Ram CV. Angiotensin receptor blockers: current status and future prospects. Am J Med 2008;121(8):656-663.

2. Ram CV, Ramaswamy K, Qian C, et al. Blood pressure outcomes in patients receiving angiotensin II receptor blockers in primary care: a comparative effectiveness analysis from electronic medical record data. J Clin Hypertens (Greenwich) 2011;13(11):801-812.

3. Maggioni AP. Efficacy of angiotensin receptor blockers in cardiovascular disease. Cardiovasc Drugs Ther 2006;20(4): 295-308.

4. Zaiken K, Cheng JW. Azilsartan medoxomil: a new angiotensin receptor blocker. Clin Ther 2011;33(11):1577-1589.

5. Bakris GL, Sica D, Weber M, et al. The comparative effects of azilsartan medoxomil and olmesartan on ambulatory and clinic blood pressure. J Clin Hypertens (Greenwich) 2011; 13(2):81-88.

6. White WB, Weber MA, Sica D, et al. Effects of angiotensin receptor blocker azilsartan medoxomil versus olmesartan and valsartan on ambulatory and clinic blood pressure in patients with stage 1 and 2 hypertension. Hypertension 2011;57(3):413-420.

7. Kurtz TW, Kajiya T. Differential pharmacology and benefit/ risk of azilsartan compared to other sartans. Vasc Health Risk Manag 2012;8:133-143.

8. Khan MA, Neckar J, Cummens B, Wahl GM, Imig JD. Azilsartan decreases renal and cardiovascular injury in the spontaneously hypertensive obese rat. Cardiovasc Drugs Ther 2014;28(4):313-322.

9. Ojima M, Hideki I, Masayuki T, et al. In vitro antagonistic properties of a new angiotensins in type 1 receptor blocker, azilsartan, in receptor binding and function studies. J Pharmacol Exp Ther 2011;336(3):801-808.

10. Ram CV. Angiotensin receptor blockers: current status and future prospects. Am J Med 2008;121:656-663.

11. Ram CVS. Calcium antagonists in the treatment of hypertension. Am J Med Sci 1985;290(8):118-132.

12. Grassi G. Sympathetic overdrive and cardiovascular risk in the metabolic syndrome. Hypertens Res 2006;29(11):839-847.

13. Takahara A. Cilnidipine: a new generation Ca channel blocker with inhibitory action on sympathetic neurotransmitter release. Cardiovasc Ther 2009;27(2):124-139.

14. Konda T, Enomoto A, Aritomi S, Niinuma K, Koganei $H$, Ogawa $\mathrm{T}$, et al. Different effects of L/N-type and L-type calcium channel blockers on the renin-angiotensinaldosterone system in SHR/Izm. Am J Nephrol 2009;30(2): 155-161.

15. Konoshita T, Makino Y, Kimura T, Fujii M, Wakahara S, Arakawa $\mathrm{K}$, et al. A new-generation N/L-type calcium channel blocker leads to less activation of the reninangiotensin system compared with conventional L-type calcium channel blocker. J Hypertens 2010;28(10):2156-2160.

16. Takeda S, Ueshiba H, Hattori Y, Irie M. Cilnidipine, the $\mathrm{N}$ - and L-type calcium antagonist, reduced on 24-hour urinary catecholamines and C-peptide in hypertensive noninsulin-dependent diabetes mellitus. Diabetes Res Clin Pract 1999;44(3):197-205.

17. Konda T, Enomoto A, Takahara A, Yamamoto H. Effects of L/N-type calcium channel antagonist, cilnidipine on progressive renal injuries in Dahl salt-sensitive rats. Biol Pharm Bull 2006;29(5):933-937.

18. Fujita $T$, Ando K, Nishimura H, Ideura T, Yasuda G, Isshiki M, et al. Antiproteinuric effect of the calcium channel blocker cilnidipine added to renin-angiotensin inhibition in hypertensive patients with chronic renal disease. Kidney Int 2007;72(12):1543-1549.

19. Tanaka M. The L/N-type calcium channel blocker, cilnidipine, reduces heart rate and albuminuria in patients with type 2 diabetes. J Int Med Res 2010;38(2):602-610.

20. Konda T, Enomoto A, Matsushita J, Takahara A, Moriyama $\mathrm{T}$. The $\mathrm{N}$ - and L-type calcium channel blocker cilnidipine suppresses renal injury in Dahl rats fed a high-sucrose diet, an experimental model of metabolic syndrome. Nephron Physiol 2005;101(1):1-13.

21. Konno Y, Kimura K. Vasodilatory effect of cilnidipine, an L-type and N-type calcium channel blocker, on rat kidney glomerular arterioles. Int Heart J 2008;49(6):723-732. 
22. Katayama K, Nomura S, Ishikawa H, Murata T, Koyabu S, Nakano T. Comparison between valsartan and valsartan plus cilnidipine in type II diabetics with normo- and microalbuminuria. Kidney Int 2006;70(1):151-156.

23. Kuroedov A, Cosentino F, Luscher TF. Pharmacological mechanisms of clinically favourable properties of a selective beta1-adrenoceptor antagonist, nebivolol. Cardiovasc Drug Rev 2004;22(3):155-168.

24. Uhlir O, Dvorak I, Gregor P, et al. Nebivolol in the treatment of cardiac failure: a double-blind controlled clinical trial. J Card Fail 1997;3(4):271-276.

25. De Boer RA, Voors AA, Van Veldhuisen DJ. Nebivolol: third-generation beta-blockade. Expert Opin Pharmacother 2007;8(10):1539-1550.

26. Pauwels PJ, Gommeren W, Van Lommen G, et al. The receptor binding profile of the new antihypertensive agent nebivolol and its stereoisomers compared with various $\beta$-adrenergic blockers. Mol Pharmacol 1988;34(6):843-851.

27. Maffei A, Lembo G. Nitric oxide mechanism of Nebivolol. Ther Adv Cardiovasc Dis 2009 Aug;3(4):317-327.

28. De Cree J, Van Rooy P, Geukens H, et al. The antihypertensive and cardiac hemodynamic effects of nebivolol. Angiology 1992;43(5):396-377.

29. CheymolG, Woestenborghs R, Shoeck, et al. Pharmacokinetics of nebivolol: a review. Drug Invest 1991;3(1):25-30.

30. Broeders MA, Doevendans PA, Bekkers BC, et al. Nebivolol: a third generation beta blocker that augments vascular nitric oxide release: endothelial beta (2)-adrenergic receptor mediated nitric oxide production. Circulation 2000;102(6):677-684.

31. Bundkirchen A, Brixius K, Bolck B, Nguyen Q, Schwinger RH. Beta 1-adrenoceptor selectivity of nebivolol and bisoprolol: a comparison of (3H) CGP 12.177 and (1251) iodocyanopindolol binding studies. Eur J Pharmacol 2003;460(1):19-26.

32. Fogari R, Zoppi A, Lazzari $\mathrm{P}$, et al. Comparative effects of nebivolol and atenolol on blood pressure and insulin sensitivity in hypertensive subjects with type II diabetes. J Hum Hypertens 1997;11(11):753-757.

33. Poirier L, Cleroux J, Nadeau A, Lacourciere Y. Effects of nebivolol and atenolol on insulin sensitivity and haemodynamics in hypertensive patients. J Hypertens 2001;19(8):1429-1435.

34. Pessina AC. Metabolic effects and safety profile of nebivolol. J Cardiovasc Pharmacol 2001;38(3):S33-35.

35. Flather M, Shibata M, Coats A, et al. Randomized trial to determine the effect of nebivolol on mortality and cardiovascular hospital admission in elderly patients with heart failure (SENIORS). Eur Heart J 2005;26(3):215-225.

36. McMurray J. Making sense of SENIORS. Eur Heart J 2005; 26(3):203-206.

37. Ram CVS. Beta-blockers in hypertension. Am J Cardiology 2010;106(12):1819-1825

38. Ram CVS. Beta-blockers in hypertension. Truths and halftruths. J Clinical Hypertens 2008;10(7):516-519.

39. Nebivolol. The first highly selective $\beta 1$-blocker with NO nitric oxide modulating properties: nebivolol monograph. Churchill Communications Europe, London; 1996. 